Jurnal Pengajian Melayu - JOMAS, Jilid 31, 2020: 151-168

\title{
PEMIKIRAN DALAM NOVEL SEMANIS KYUHO KARYA GHAZALI LATEH
}

\author{
(THOUGHTS IN THE NOVEL 'SEMANIS KYUHO’BY GHAZALI LATEH
}

\author{
Nurhamizah Hashim \\ Akademi Pengajian Melayu, Universiti Malaya \\ Kuala Lumpur \\ Malaysia \\ aaee@um.edu.my \\ Eizah Mat Hussain \\ Akademi Pengajian Melayu, Universiti Malaya \\ Kuala Lumpur \\ Malaysia \\ eizah@um.edu.my \\ Asbah Razali \\ Fakulti Sastera dan Sains Sosial, Universiti Malaya \\ Kuala Lumpur \\ Malaysia \\ asbahrazali@um.edu.my \\ Natasah Mat Madmin \\ Akademi Pengajian Melayu, Universiti Malaya \\ Kuala Lumpur \\ Malaysia \\ natasahm06@gmail.com
}

Received: 11 August 2020; Accepted: 9 November 2020

\begin{abstract}
Thinking is the process of building knowledge and understanding that involves mental activity in the human brain. During the process of thinking, the human brain will attempt to understand external stimulation received through the senses, form concepts, make interpretations and react based on existing experiences in memory. The concept of thinking is very broad and can be explained using various approaches. Hence, this study examined the aspects of thinking in the teen novel 'Semanis Kyuho' by Ghazali Lateh (2016). The novel won the Utusan Group Literature Prize in 2015. The objectives of this study were to identify, analyse and formulate aspects of thinking found in the abovementioned youth novel. The approach utilised the general concept of thought and thinking in Malay literature as suggested by academics like Dewey (1910) from the West and Mohd Yusof Othman (1998), Zainal Kling (1993), Hashim Awang (1997) and several others from the East. The study also involved only literary research and text analysis. Findings show two dominant aspects of thinking within the novel, namely thinking from the aspect of socio-economic issues such as poverty and hardship faced by villagers and the aspect of socio-culture such as the societal emphasis on education to attain a brighter future.
\end{abstract}

Keywords: Thought, Teen Novel, Semanis Kyuho, Socio-economics, Socio-Culture.

e ISSN 2735 - 1904

https://doi.org/10.22452/JOMAS.vol31no1.10 


\begin{abstract}
Abstrak
Pemikiran merupakan proses membina ilmu dan kefahaman yang melibatkan aktiviti mental dalam otak manusia. Semasa berfikir, otak manusia akan bertindak dengan usaha memahami rancangan luar yang diterima melalui deria, membentuk konsep, membuat tafsiran dan tindak balas berdasarkan pengalaman yang sedia ada dalam ingatan. Konsep pemikiran mempunyai pengertian yang sangat luas dan boleh diterangkan dalam pelbagai pendekatan. Oleh yang demikian, kajian ini secara keseluruhannya mengkaji aspek pemikiran yang terdapat dalam novel remaja bertajuk Semanis Kyuho karya Ghazali Lateh (2016). Novel ini telah memenangi hadiah penghargaan kategori novel remaja Hadiah Sastera Kumpulan Utusan pada tahun 2015. Tujuan kajian dilakukan adalah untuk mengenal pasti, menganalisis serta merumuskan aspek pemikiran yang terdapat dalam novel remaja Semanis Kyuho karya Ghazali Lateh. Kajian ini menggunakan pendekatan konsep pemikiran secara umum serta pemikiran dalam kesusasteraan Melayu mengikut pandangan daripada tokoh dari barat seperti Dewey (1910) dan tempatan seperti Mohd Yusof Othman (1998), Zainal Kling (1993), Hashim Awang (1997) dan beberapa tokoh lain. Metodologi kajian melibatkan kaedah kepustakaan serta kaedah analisis teks. Dapatan kajian menunjukkan terdapat dua aspek pemikiran yang dominan dalam novel Semanis Kyuho ini, iaitu pemikiran dari aspek sosioekonomi, seperti kemiskinan dan kesempitan hidup penduduk kampung dan yang kedua pemikiran dari aspek sosiobudaya, seperti masyarakat yang mementingkan pendidikan untuk masa hadapan.
\end{abstract}

Kata Kunci: Pemikiran, Novel Remaja, Semanis Kyuho, Sosioekonomi, Sosiobudaya.

\title{
Pengenalan
}

Karya sastera, terutamanya novel merupakan satu medium yang digunakan oleh penulis untuk menyampaikan pemikiran mereka. Tanpa pemikiran dan idea daripada pengarang, sesuatu karya dan penulisan tidak akan berjaya dihasilkan (Normaizatul Anis Ahmad \& Halis Azhan Mohd Hanafiah, 2019 p. 169). Hal ini kerana, pemikiran merupakan proses membina ilmu dan kefahaman yang melibatkan aktiviti mental dalam otak manusia. Semasa berfikir, otak manusia akan bertindak dengan usaha memahami rangsangan luar yang diterima melalui deria, membentuk konsep, membuat tafsiran dan tindak balas berdasarkan pengalaman yang sedia ada dalam ingatan. Terdapat banyak definisi serta konsep pemikiran yang dikemukakan oleh ahli-ahli psikologi, terutamanya sejak kurun ke-20. Misalnya, Dewey (1910) mendefinisikan pemikiran sebagai aktiviti mental dalam sesuatu proses untuk menyelesaikan masalah yang dihadapi.

Menurut pandangan Islam, berfikir ialah fungsi akal yang mengawal tenaga supaya otak manusia dapat bekerja dan beroperasi dengan sebaik-baiknya. Tenaga ini diperoleh melalui tafakur (merenung). Berdasarkan pandangan dan definisi yang telah dinyatakan, pemikiran boleh dirumuskan sebagai suatu proses yang menggunakan minda untuk mencari makna dan penyelesaian terhadap sesuatu keraguan atau masalah yang timbul dengan menggunakan pelbagai cara. Selain itu, berfikir juga berkaitan dengan soal membuat pertimbangan dan keputusan serta refleksi yang logikal dan munasabah terhadap proses yang dialami.

Novel pada masa kini termasuk mengalami perkembangan yang cukup signifikan di berbagai-bagai belahan dunia. Dari sebuah novel, seseorang mampu mengekspresikan dirinya, 
fikirannya, bahkan dalam suatu cerita yang bersifat fiksyen atau pun cerita yang sifatnya didasarkan pada kisah nyata (M. Jandra. 2010, p. 108). Berdasarkan novel yang dipilih, wujud dua pemikiran yang paling dominan, iaitu aspek sosioekonomi dan aspek sosiobudaya. Pemikiran tersebut dianalisis dalam karya bertujuan untuk melihat perkembangan tema yang disampaikan dalam novel. Sehubungan itu, aspek pemikiran yang ditonjolkan dalam novel tersebut dapat memaparkan tujuan atau idea pengarang dalam menyampaikan sesuatu isu yang berlaku dalam masyarakat.

\section{Sorotan Kajian}

Terdapat beberapa kajian yang menyentuh aspek pemikiran dalam bidang kesusasteraan Melayu telah dihasilkan oleh para pengkaji. Antaranya kajian oleh Nurmaizatul Anis Ahmad dan Halis Azhan Mohd Hanafiah (2019) yang bertajuk "Pemikiran Islam dalam Konteks Sosioekonomi dalam kumpulan cerpen Cahaya Pelita Nurani" dalam Jurnal Pengajian Melayu. Fokus kajian ini adalah untuk mengklasifikasi dan menganalisis pemikiran Islam dalam konteks sosioekonomi untuk melihat perkaitannya dengan masyarakat yang terdapat dalam enam buah cerpen yang dipilih dalam kumpulan cerpen Cahaya Pelita Nurani (2015). Kaedah yang digunakan dalam kajian ini adalah kaedah kepustakaan, menganalisis kandungan teks dan pengaplikasian Pendekatan Kemasyarakatan. Hasil kajian menunjukkan bahawa pemikiran Islam dalam konteks sosioekonomi membincangkan persoalan kemiskinan dan penindasan, kesamarataan hak, pembangunan, pekerjaan dan perbandaran sesuai diterapkan dengan Pendekatan Kemasyarakatan.

Seterusnya, kajian oleh Noorhazwany Ariffin \& Noryamisma Ismail (2014) bertajuk "Pemikiran Marzuki Ali dalam Khazanah Segala Rimbun dari Aspek Teori Pengkaedahan Melayu" dalam Jurnal Pengajian Melayu. Kajian ini bertujuan untuk mengenal pasti dan menganalisis pemikiran dalam Khazanah Segala Rimbun karya Marzuki Ali. Kajian ini menggunakan Teori Pengkaedahan Melayu untuk menganalisis data. Dapatan kajian menunjukkan bahawa Marzuki Ali merupakan seorang penyair yang tekun memerhatikan tingkah alam dan mempelajari perlakuan alam untuk melahirkannya dalam metafora bagi menyampaikan maksud puisi. Selain alam, pemikiran dalam puisinya turut dibentuk oleh agama Islam. Dua faktor ini, iaitu alam dan agama Islam, mencorakkan kreativitinya. Mesej-mesej yang baik dan positif adalah menepati ciriciri yang digariskan oleh Teori Pengkaedahan Melayu yang mengikut Hashim Awang sejak zaman berzaman merupakan sastera yang membawa mesej ke arah kebajikan.

Kajian pemikiran dalam novel dilakukan oleh Marzalina Mansor, Nor Hafidah Ibrahim \& Hasmawati Hassan (2016) dengan tajuk kajian "Pemikiran dalam Novel Sebalik Yamashita dan Percivel". Kajian mereka bertujuan untuk mengkaji dan menganalisis aspek pemikiran pengarang dalam novel Sebalik Yamashita dan Parcivel (2015) karya Shaari Isa. Kaedah kajian ini dilakukan secara kualitatif, iaitu kajian kepustakaan dan analisis teks. Hasil kajian mendapati pemikiran yang ditonjolkan oleh pengarang ialah pemikiran kolonialisme dan imperialisme, pemikiran politik dan kepimpinan, dan pemikiran sejarah.

Samsudin Ahmad (2000) telah membincangkan aspek pemikiran dan bentuk luaran sajaksajak Masuri S.N. dari tahun 1945 hingga 1995. Sajak-sajak tersebut dibahagikan kepada dua era, iaitu era sebelum merdeka dan era selepas merdeka. Hasil penelitian, pengkaji mendapati wujud empat aspek pemikiran utama dalam sajak-sajak tersebut, iaitu nasionalisme, kemasyarakatan, introspeksi diri, dan pemikiran tentang alam. Pendekatan stilistik telah digunakan dalam 
menganalisis aspek-aspek tersebut. Hasil kajian menunjukkan bahawa perubahan sajak sebelum merdeka dan selepas merdeka bukan sahaja berlaku dari aspek bentuk luaran sajak tetapi perubahan yang ketara turut berlaku dalam aspek pemikiran. Berdasarkan sorotan kajian yang dikemukakan, ternyata bahawa terdapat banyak kajian berkaitan pemikiran dalam kesusasteraan Melayu yang telah dilakukan oleh sarjana tempatan. Namun, kajian ini berbeza daripada kajian-kajian sedia ada kerana pengkaji memanfaatkan novel remaja Semanis Kyuho (2016) yang belum pernah lagi dikaji oleh mana-mana pengkaji, selain memberi tumpuan terhadap analisis pemikiran yang ingin disampaikan oleh penulisnya.

\section{Konsep Pemikiran}

Pemikiran merupakan proses yang menggunakan akal untuk menyelesaikan masalah. Proses ini melibatkan aktiviti-aktiviti menyusun idea-idea atau perkara-perkara yang tersembunyi, membuat kesimpulan untuk mendapatkan ilmu atau kemahiran baru yang boleh digunakan untuk penyelesaian masalah yang kian mencabar. Pemikiran kritis didefinisikan sebagai proses pemikiran yang bermula dengan proses menyoal kepada masalah bagi mendapatkan serta mempertingkat pemahaman. Hal ini melibatkan tiga jenis aktiviti mental, iaitu analisis, sintesis dan penilaian. Pemikiran kritis menggalakkan individu menganalisis sesuatu pernyataan dengan berhati-hati, mencari bukti yang sah serta kukuh sebelum membuat kesimpulan. Pemikiran kritis juga mendorong individu bersifat rasional seperti menaakul secara kritis, malah dapat meneliti pengalamannya, menilai dan menimbang pelbagai pendapat dan idea sebelum membuat keputusan.

Pemikiran mempunyai pengertian yang luas dan boleh diterangkan dalam pelbagai pendekatan. Namun, berfikir merupakan suatu usaha untuk meningkatkan pengetahuan seseorang. Oleh yang demikian, hanya orang yang mampu berfikir boleh melakukan perubahan dan boleh menjana aktiviti yang bersifat kreatif dan membangun. Kemampuan dan keluasan berfikir tidak akan menjadikan seseorang itu stereotaip dalam tindakan dan amalannya. Konsep pemikiran pernah dijelaskan oleh Zainal Kling (1993, p. 400) sebagai kegiatan untuk membentuk sesuatu sistem tanggapan yang akan menjadi rangka berfikir yang wajar bagi semua anggota masyarakat.

Menurut Hashim Awang (1997, p. 15), terdapat dua jenis pemikiran dalam kesusasteraan Melayu yang juga merangkumi novel Melayu. Pertama, pemikiran yang ditimbulkan oleh pelbagai watak dalam sesuatu cerita, lakonan dan sajak. Kedua, pemikiran yang membangunkan tema utama atau makna daripada keseluruhan karya. Kedua-dua jenis pemikiran tersebut diwujudkan oleh penulis atau pengkarya. Apabila pemikiran dinyatakan melalui watak tertentu dalam sesebuah karya, pembaca harus berhati-hati supaya tidak menjadikannya sebagai satu nilai yang benar. Pemikiran dalam novel bertujuan sama ada membiarkan watak yang kurang penting melahirkannya atau untuk mencipta satu pertentangan dengan satu pandangan yang dikemukakan oleh pihak lain, oleh watak-watak yang lebih berkaliber. Justeru, sesuatu pemikiran dalam novel mestilah dipertimbangkan hanya dalam konteks dan hubungannya dengan keseluruhan karya. Hal yang lebih penting ialah bagaimana terkawal atau baiknya sesuatu pemikiran yang disampaikan oleh penulis kepada khalayak. Pemikiran adalah peristiwa yang tersurat dan tersirat dari peristiwa

yang hendak dikemukakan. Dengan demikian, apa-apa yang ingin disampaikan oleh pengarang merupakan pemikiran, iaitu proses menyampaikan mesej yang terkandung dalam fikiran penyair atau pengarang (Noor Hazwany Haji Arifin \& Noryamisma Ismail 2014, p. 147).

e ISSN 2735 - 1904

https://doi.org/10.22452/JOMAS.vol31no1.10 
Menurut S. Othman Kelantan (1997, p. 269) pemikiran bermakna idea yang wujud daripada golongan intelektual yang menggunakan fakulti kritikal dalam mindanya untuk memikirkan sesuatu masalah dalam masyarakatnya. Pemikirannya itu disebarkan dalam lingkungan masyarakatnya atau di luar daripada masyarakatnya. Mungkin disebabkan memikirkan ancaman yang muncul pada zamannya, golongan intelektual ini merakamkan ketidaksenangan dan kegelisahannya dalam bentuk novel. Pemikiran yang tersembunyi dalam novel ini dikaji untuk melihat keupayaan dan keunggulan pengarang Melayu meluahkan perasaan mereka yang beragam dan kompleks itu. Justeru, pemikiran dalam novel juga dapat dilihat melalui watak-watak yang beraneka ragam. Lantaran itu, Ali Ahmad (1978, p. 3) mengatakan watak-watak dalam novel biasanya ramai dan diberikan sifat yang pelbagai. Perhubungan antara watak ini lebih luas dan mengakibatkan konflik yang berlanjutan menjadikan timbulnya permasalahan yang perlu diselesaikan. Sekiranya watak hanya seorang dua, maka masalah yang dihadapinya lebih luas dan memerlukan penghuraian yang mendalam. Oleh yang demikian, peristiwa-peristiwa dalam novel banyak dan berpanjangan dengan peringkat-peringkat turun naiknya. Dengan kata lain jalan ceritanya mempunyai plot dan anak plot.

Pemikiran dalam novel dapat dilihat apabila pengarang mendedahkan dan menghubungkan pertalian antara sesuatu peristiwa atau situasi. Kemudian, pengarang mencari sebab akibat yang wujud akibat sesuatu peristiwa untuk memahami punca sesuatu kejadian. Sesudah menilai, pengarang mula menggerakkan sesuatu yang baru diperolehnya dan dikongsi bersama-sama agar mendapat manfaat kepada pembaca. Lantaran itu, idea yang diperoleh dicernakan ke dalam karya dengan cara yang kreatif serta dapat dilihat secara tersirat dan tersurat. Dari sini, pembaca atau pengkaji sastera akan dapat melihat cara-cara pengarang menggunakan kebijaksanaan akalnya dalam memperlihatkan sesuatu fenomena.

Beyer (1985) berpendapat, pemikiran kritis adalah kebolehan manusia untuk membentuk konsep, memberi sebab atau membuat penentuan. Pascarella dan Terenzini $(1991,2005)$ pula mendefinisikan pemikiran kritis sebagai kebolehan individu untuk mengenal pasti isu-isu dan membuat andaian untuk dibahaskan serta mengenal pasti hubungan penting untuk mendapatkan rumusan yang tepat daripada maklumat yang sedia ada. Seterusnya, menurut Dewey (1993), pemikiran kritis adalah berfikir secara serius dan mendalam serta membuat pertimbangan daripadanya, manakala Marlina dan Shaharom (2007) mendefinisikan kemahiran berfikir kritis sebagai kecekapan atau keupayaan menggunakan minda untuk menilai kemunasabahan dan kewajaran sesuatu idea, meneliti kebernasan, kebaikan dan kelemahan sesuatu hujah dan membuat pertimbangan yang wajar dengan menggunakan alasan dan bukti yang munasabah.

Tujuan utama proses pemikiran adalah untuk membina pengetahuan, pemahaman dan melibatkan aktiviti mental murid-murid. Proses pemikiran dan usaha oleh otak adalah untuk mencari rasional. Oleh itu, proses ini merupakan suatu aktiviti mental yang sangat penting dalam proses penyelesaian masalah. Aktiviti ini juga boleh ditafsirkan sebagai kebolehan otak dalam pelbagai kemahiran berfikir. Semasa berfikir, otak akan bertindak sebagai usaha untuk memahami rangsangan-rangsangan luar yang diterima oleh deria. Setelah itu, otak menukar rangsanganrangsangan tersebut ke dalam bentuk konsep, membuat tafsiran dan bertindak balas berdasarkan pengalaman-pengalaman yang sedia ada dalam ingatan. 
Berdasarkan penerangan tokoh-tokoh berkaitan konsep pemikiran tersebut, maka dapatlah disimpulkan bahawa pemikiran adalah sesuatu tindak balas yang terjadi pada seseorang yang berinteraksi dengan persekitaran, masyarakat atau individu. Malah, sesuatu yang berlaku itu akan membuahkan satu kefahaman yang boleh dilihat jelas oleh seseorang. Misalnya, seseorang pengarang yang menghasilkan sebuah karya berdasarkan pemikiran-pemikiran yang dilihat daripada pengalaman hidupnya. Pemikiran tersebut boleh dilihat dalam karya-karya sastera seseorang pengarang yang menggunakan watak-watak dan menghubungkaitkannya dengan sebab dan akibat untuk menyampaikan pemikiran pengarang. Malah, seseorang yang membaca karya sekali gus akan merangsang otak mereka untuk berfikir tentang mesej yang hendak disampaikan oleh penulis dalam karya tersebut. Oleh itu, aspek pemikiran sangat penting dalam sesebuah karya ataupun sesuatu penyampaian. Keadaan ini mencetuskan daya berfikir yang tinggi dan kreatif dalam kalangan para pembaca sesuatu karya itu. Kebijaksanaan pengarang dalam mewujudkan unsurunsur pemikiran dalam karya telah menjadikan karya mereka lebih bermutu bukan sahaja dari segi pemasaran, malah dari segi membangunkan aspek lahiriah dan rohaniah khalayak pembaca.

\section{Metodologi Kajian}

Kajian ini akan melibatkan satu kaedah, iaitu kaedah kepustakaan sahaja. Dalam kaedah kepustakaan data sekunder akan diperoleh, iaitu melibatkan pemerolehan data daripada manuskrip. Selain itu, rujukan terhadap kajian yang berkaitan dengan bidang akan dilakukan untuk mendapatkan bahan tambahan. Konsep asas yang berkaitan dengan kajian akan difahami dan diperhalusi bagi membantu kajian ini dilakukan. Selain itu, kajian ini melibatkan dua kaedah kajian, iaitu kaedah pemerolehan data dan kaedah menganalisis data. Kaedah pemerolehan data akan dilakukan terlebih dahulu yang mana data akan diperoleh daripada novel remaja Semanis Kyuho karya Ghazali Lateh (2016). Kemudian kaedah menganalisis data akan dilakukan berdasarkan data yang telah diperoleh.

Metodologi kajian ini dilakukan bagi mencapai objektif kajian, iaitu mengenal pasti, menganalisis dan merumuskan aspek pemikiran yang terdapat dalam novel remaja Semanis Kyuho karya Ghazali Lateh. Hal ini kerana pengarang menyampaikan pemikiran berkaitan isu-isu yang berlaku dalam masyarakat menerusi watak-watak yang terdapat dalam karyanya.

\section{Dapatan Kajian}

Hasil kajian mendapati bahawa pemikiran yang paling dominan ingin disampaikan oleh penulis novel Semanis Kyuho ini ialah aspek sosioekonomi dan aspek sosiobudaya.

\section{Aspek Sosioekonomi}

Secara konseptualnya, sosioekonomi terdiri daripada gabungan dua konsep, iaitu sosial dan ekonomi. Sosial merujuk kepada struktur dan sifat-sifat kelompok manusia yang saling berinteraksi dan berhubungan antara satu sama lain. Lebih jelas lagi, aspek sosial merangkumi segala interaksi melalui komunikasi sesama penduduk tidak kira komunikasi jenis sehala atau dua hala (Yusof, 2010). Aspek sosioekonomi dalam kajian ini dianalisis dari segi sikap rajin bekerja untuk kelangsungan hidup dan kemiskinan serta kesempitan hidup penduduk kampung. 


\section{Sikap Rajin Bekerja untuk Kelangsungan Hidup}

Sikap rajin bekerja penting untuk meneruskan kelangsungan hidup dan sikap tersebut perlu ada pada semua orang yang ingin meningkatkan tahap sosioekonomi mereka. Namun, begitu sikap rajin juga kadangkala sukar untuk dibentuk, bahkan sukar untuk dilaksanakan. Mereka yang tekun berusaha dan berbekalkan sifat ikhlas yang membenih dalam hati mampu membina dan membentuk sikap rajin dalam kehidupan. Sesungguhnya, buah kepada sifat ikhlas juga adalah datangnya daripada sikap rajin melakukan sesuatu usaha untuk mencapai matlamat, iaitu ikhlas melakukan sesuatu kerana minat terhadap sesuatu yang diusahakan. Maka apabila bersatunya sikap rajin yang ditanam dan dibenihkan dengan keikhlasan di hati, maka kita akan beroleh hasil yang bukan semua orang mampu mengecapinya, iaitu kebahagiaan. Kebahagiaan ini merangkumi kebahagiaan di dunia dan di akhirat. Dengan adanya kerajinan dan keikhlasan ini, lahirlah masyarakat yang harmoni dan mendapat kejayaan di dunia dan akhirat. Perkataan rajin membawa maksud suka bekerja (belajar dl1), giat, bersungguh-sungguh, tekun (Kamus Dewan Bahasa Edisi Keempat, 2010).

Sebagai seorang manusia, kita tidak akan terlepas daripada melakukan sesuatu pekerjaan yang kadangkala mengundang perasaan rajin dan malas. Perasaan ini akan menyebabkan kualiti sesuatu kerja itu bermutu tinggi atau sebaliknya. Jika seseorang rajin dan tekun melakukan sesuatu tugas, maka hasilnya juga akan baik. Namun, jika seseorang itu melakukan sesuatu pekerjaan sekadar 'melepaskan batuk di tangga', dalam erti kata lain, malas, maka hasil kerjanya sudah tentu tidak memuaskan. Dalam novel Semanis Kyuho, sikap rajin untuk kelangsungan hidup telah digambarkan menerusi watak Pak Sin dan Sani. Mereka tidak pernah mengeluh dengan kerja yang mereka lakukan walaupun pekerjaan itu tidak memberi banyak keuntungan atau hasil kepada mereka. Bagi mereka, sesuatu pekerjaan hendaklah dilakukan dengan bersungguh-sungguh supaya mendapatkan hasil dan hasil tersebut akan dijadikan bekalan untuk mereka meneruskan hidup. Keadaan ini dapat dilihat dalam petikan berikut:

"Pak Sin pula telah mengubah haluan. Kehidupannya kini lebih banyak tertumpu di bahagian timur kampung. Selain menoreh di kawasan tanah rizab estet, Pak Sin menanam cili di celah-celah pokok getah yang tumbuh sendiri. Ada cili api dan cili merah. Sani sering membantu terutama memetik cili. Sehingga pijar tangannya, jika memetik cili api. Apatah lagi jika ada pesanan dari kedai mamak Zakir yang sering membeli cili tanaman Pak Sin.”

(Semanis Kyuho, 2016, p. 5-6)

Berdasarkan petikan tersebut, watak Pak Sin dan Sani digambarkan mempunyai sikap yang sangat rajin melakukan pelbagai pekerjaan untuk menjana pendapatan dan meneruskan hidup. Kerajinan dan kreativiti Pak Sin dalam menjalani kehidupan di kampung itu menjadikan mereka tidak begitu tertekan seperti keluarga penduduk kampung yang lain. Ramai penduduk kampung yang berpindah ke kampung sebelah kerana tanah di Kampung Bukit Nibung tidak sesubur dahulu. Namun, Pak Sin tetap tinggal di kampung itu. Biarlah orang lain berpindah, namun dia tetap setia mendiami kampung itu. Biarlah sawah di lembah tidak lagi dapat dikerjakan biarlah padi ditanam tidak menjadi. Namun, dugaan itu tidak melemahkan semangat Pak Sin dan keluarganya untuk mencari rezeki dengan pelbagai cara.

Pak Sin memang terkenal dengan sikapnya yang rajin dalam melakukan sesuatu pekerjaan sebab itulah penduduk kampung kagum melihat kerajinan Pak Sin. Sani turut mewarisi sikap 
tersebut. Sani sering membantu Pak Sin dalam mencari rezeki. Bukan Pak Sin dan Sani sahaja yang bekerja keras. Mak Dah, ibu Sani juga tidak kurang sumbangannya untuk mencari rezeki. Kepandaian Mak Dah membuat ikan pekasam sepat memang tidak dapat ditandingi. Mak Dah akan memproses ikan sepat dan Sani sering memerhatikan ibunya menyediakan pekasam ikan. Ikan-ikan dibersihkan dan disimpan di dalam tempayan kecil di dapur. Ternyata permintaan terhadap ikan pekasam Mak Dah sangat menggalakkan, paling tidak ikan pekasam itu dijual di kedai Mamak Zakir.

Jelaslah bahawa, pemikiran kerajinan bekerja untuk kelangsungan hidup yang disampaikan oleh pengarang melalui watak Pak Sin dan keluarganya memberi kesan besar dalam realiti kehidupan manusia pada masa ini. Hal ini demikian kerana, kebanyakan manusia pada era ini tidak mengamalkan sikap sedemikian dalam melakukan sesuatu pekerjaan. Berbeza dengan Pak Sin dan Sani yang berhempas pulas untuk membanting tulang dalam menyara kehidupan mereka. Oleh itu, sikap kerajinan dapat menjadikan seseorang tidak mudah berputus asa dalam melakukan sesuatu dan mampu merangsang fikiran manusia untuk lebih kreatif dan berinovasi. Pemaparan watak-watak ini dan kisah hidup mereka membayangkan bahawa tidak mustahil manusia dapat mengubah taraf hidup hidup mereka dengan kesungguhan dan kerajinan yang tinggi.

\section{Kemiskinan dan Kesempitan Hidup Penduduk Kampung}

Kesempitan bermaksud keadaan atau hal sempit dan mengalami keadaan sempit seperti kekurangan wang, kesempitan hidup. Kesempitan hidup selalunya berpunca akibat peperangan, kepincangan hidup dan sebagainya (Kamus Pelajar Edisi Kedua, 2015). Kesempitan hidup berkait rapat dengan konsep kemiskinan. Menurut Lauer (1971), Wilson dan Aponte (1985), kemiskinan berkongsi elemen yang sama, iaitu boleh berpunca daripada kesan peperangan, sikap malas, faktor usia, fizikal kurang upaya dan tidak bekerja atau menganggur. Kemiskinan adalah suatu masalah umum, maka masalah ini perlu ditangani oleh kerajaan. Katz (1989) menyatakan bahawa punca kemiskinan sebahagiannya adalah disebabkan oleh kegagalan dasar kerajaan untuk mengubati punca kemiskinan dan membiarkan masalah ini berakar umbi serta berlarutan. Oleh itu, demi meneruskan kelangsungan hidup masyarakat miskin sudah tidak mempunyai pilihan lain. Mereka terpaksa berkerja dan berusaha lebih keras untuk mengubah kehidupan mereka. Hal ini kerana dalam meneruskan kehidupan pada masa kini amat besar cabarannya terutama dari segi kewangan.

Kesempitan hidup turut digambarkan oleh pengarang dalam novel Semanis Kyuho melalui kedaifan watak-watak dalam novel tersebut. Sani sudah diajar bersusah sejak kecil, kawasan tanah sawah yang tidak subur itu telah menjadi gelanggang dia bertarung dengan kesusahan. Pak Sin banyak mengajarkan Sani untuk mengerjakan sawah kerana sawah itulah yang menjadi punca pendapatan mereka. Kesempitan hidup dapat dilihat dengan lebih jelas apabila Pak Sin terlantar sakit di rumah dan teringin memakan segugus anggur. Namun, kesempitan hidup yang dimiliki oleh mereka menyebabkan Sani tidak dapat menunaikan hasrat bapanya untuk memakan anggur.

"Permintaan Pak Sin membuntukan Sani seketika. Tidak pernah terbayang bapanya akan meminta untuk makan anggur. Buah import itu bukan murah harganya. Hanya makanan orang-orang kaya. Makanan orang-orang bandar. Orang kampung seperti mereka tidak pernah berharap untuk makan anggur."

(Semanis Kyuho, 2016, p. 11)

e ISSN 2735 - 1904

https://doi.org/10.22452/JOMAS.vol31no1.10 
Berdasarkan petikan tersebut, Sani terkilan kerana mendengar permintaan bapanya kerana bapanya merupakan seorang yang sangat berjimat. Pak Sin marah jika anaknya bermewah-mewah terutama untuk membeli makanan dan pakaian. Dengan kesempitan hidup yang mereka alami sukar baginya untuk menunaikan keinginan bapanya. Namun, bapanya sedang sakit tenat dan selalunya permintaan orang sakit perlu dipenuhi. Sekiranya ada sekalipun buah anggur yang diinginkan bapanya, dari mana dia akan mendapatkan wang untuk membeli buah anggur yang mahal itu. Namun, itu merupakan permintaan besar bapanya yang tidak patut diabaikan.

Sani pun berusaha untuk mendapatkan anggur di pekan. Ketika Sani mencari buah anggur, dia terserempak dengan Dalila. Dalila ialah anak gadis yang dikenalinya sejak kecil, anak Pak Halim dan keluarga orang berada. Di kesempatan itu, Sani meminta bantuan Dalila untuk meminjamkan sedikit wang kepadanya untuk membeli buah anggur. Pada mulanya Dalila bersetuju untuk membelikan Sani buah anggur tetapi pada masa yang sama, sebelum Dalila memberikan anggur itu kepada Sani dia telah dihasut oleh Rizwan agar tidak memberikan anggur tersebut. Sehinggalah Dalila termakan hasutan Rizwan dan tidak memberikan anggur itu kepada Sani. Kesedihan dan perasaan aib meresap di seluruh tubuh Sani. Sia-sia usahanya untuk mendapatkan segugus anggur. Keadaan ini jelas menunjukkan kesempitan hidup yang dihadapi oleh keluarga Sani.

Lantaran usaha yang dilakukan oleh Sani gagal dalam mendapatkan segugus anggur daripada pertolongan Dalila, Sani memulakan semula pencariannya. Keadaan Pak Sin semakin nazak, Sani sempat memangku kepala Pak Sin sambil mengajar melafazkan dua kalimah syahadah sebelum denyut nadi Pak San terhenti. Belum sempat segugus anggur itu dihidangkan, Pak Sin telah pergi meninggalkan Sani dan Mak Dah. Keadaan ini telah meninggalkan kesedihan dan kesayuan yang besar dalam jiwa Sani. Arwah bapanya telah pergi sebelum dia berhasil menunaikan permintaan kecil, iaitu segugus anggur. Betapa kejamnya kemiskinan yang tidak membenarkan Sani menunaikan permintaan bapanya dan kejamnya manusia berada yang sewenang-wenangnya memberikan pengharapan yang tidak pasti dan pertolongan yang tidak ikhlas.

Jelaslah bahawa, pemikiran tentang kesempitan hidup yang dipaparkan dalam novel Semanis Kyuho memberi pandangan jelas dalam membezakan golongan miskin dan golongan berada. Kesempitan hidup yang dialami oleh watak dalam novel ini memperlihatkan bahawa masyarakat pada masa itu mengalami kesusahan dan kesempitan hidup, sekali gus menggambarkan gaya hidup golongan miskin. Sememangnya banyak perkara atau cara yang boleh dilakukan untuk keluar daripada cengkaman kesempitan hidup. Nyatalah kesempitan hidup ini tidak akan selamanya bersarang dalam kehidupan seseorang melainkan dia berusaha untuk keluar dari sarangnya.

\section{Aspek Sosiobudaya}

Sosiobudaya didefinisikan sebagai hubungan masyarakat dengan budaya seperti cara hidup, adat istiadat dan lain-lain (https://prpm.dbp.gov.my/cari1 ?keyword=sosiobudaya). Sosiobudaya merujuk kepada amalan atau gaya hidup dan peradaban yang merangkumi pelbagai aspek dalam kehidupan. Aspek sosiobudaya yang dianalisis ialah masyarakat yang mementingkan pendidikan, masyarakat yang tolong-menolong, masyarakat yang mempunyai sikap bersungguh-sungguh dalam mencapai impian dan masyarakat yang mempunyai sifat hasad dengki. 


\section{Masyarakat yang Mementingkan Pendidikan Untuk Masa Hadapan}

Pendidikan merupakan satu daripada penanda aras terpenting dalam menentukan kualiti hidup manusia. Pendidikan mampu mengorak langkah terhadap pencapaian pekerjaan yang diingini. Pencapaian dalam pendidikan menggambarkan tingginya ilmu pengetahuan yang dimiliki oleh seseorang dalam bidang yang diceburi malah merupakan hasil ilmu yang diperoleh. Masyarakat yang bertamadun merupakan masyarakat yang berpendidikan dan mempunyai keyakinan diri yang tinggi untuk menjalani kehidupan yang serba optimis. Pendidikan merupakan pemangkin terhadap kehidupan manusia yang lebih sejahtera dan ke arah peningkatan hidup yang lebih sempurna, bijak dalam pengurusan dan pengendalian ekonomi keluarga, kewibawaan dalam hubungan sesama manusia serta keseimbangan diri dari segi fizikal, mental dan spiritual.

Pendidikan mempunyai impak yang besar ke atas pelbagai peluang kehidupan manusia untuk memperoleh dan mengekalkan kualiti kehidupan. Pendidikan boleh meningkatkan keupayaan seseorang individu dalam mengurus hidup yang berkualiti kerana faktor ekonomi dan sosial bergantung kepada pendidikan yang diterima. Pendidikan berkualiti sangat efektif bagi menentang kemiskinan, membina demokrasi, dan membentuk masyarakat yang sejahtera. Ross dan $\mathrm{Wu}$ (1996) menyatakan bahawa pendidikan mempunyai impak yang besar ke atas pelbagai peluang kehidupan manusia untuk memperoleh dan mengekalkan kualiti kehidupan. Pendidikan sangat penting dalam konteks kesejahteraan ekonomi kerana boleh memimpin individu ke arah memperoleh pendapatan tidak terhad (Marx, 1964, 1971), serta mampu meningkatkan perasaan kawalan-diri seseorang (Christoffel dan Gallagher, 2006).

Menerusi novel Semanis Kyuho karya Ghazali Lateh, pemikiran mengenai kepentingan pendidikan untuk masa hadapan turut ditonjolkan oleh pengarang. Walaupun kehidupan keluarga Sani serba kekurangan, namun mereka amat mementingkan pendidikan. Keadaan ini dapat dilihat apabila Pak Sin telah menyimpan wang sebelum meninggal untuk menanggung yuran peperiksaan Sani. Hal ini, jelas menunjukkan bahawa dalam kehidupan yang susah pun mereka masih memikirkan soal pendidikan. Bahkan, Sani juga membuat permohonan untuk meneruskan pelajaran di Universiti Putra Malaysia dalam bidang pertanian, kerana baginya dia perlu melengkapkan dirinya dengan ilmu, dia tahu dia tidak akan mampu bergerak sekiranya tiada ilmu. Impian Sani untuk membuka ladang anggur juga telah menjadi pemangkin semangat untuk mendapatkan ilmu pendidikan. Perkara ini digambarkan dalam petikan berikut:

"Dia sedang menantikan keputusan permohonannya untuk melanjutkan pelajaran. Dia memohon untuk mengikut kursus Diploma Pertanian di Universiti Putra Malaysia. Keputusannya yang baik dalam mata pelajaran Sains Pertanian menyebabkan dia memohon kursus berkenaan. Malah cikgu Tan sendiri yang menasihatinya adar dia memilih kursus dalam bidang pertanian. Baginya dia perlu melengkapkan dirinya dengan pengetahuan dalam bidang pertanian sebelum menjadikan bidang itu sebagai sumber rezekinya nanti. Dalam apa-apa pun bidang diceburi, perkara paling asas adalah ilmu. Ilmu yang bermanfaat ialah ilmu yang diamalkan."

(Semanis Kyuho, 2016, p. 58)

e ISSN 2735 - 1904

https://doi.org/10.22452/JOMAS.vol31no1.10 
Petikan tersebut jelas menunjukkan bahawa Sani dan keluarganya sangat mementingkan pendidikan kerana bagi mereka pendidikan yang sempurna mampu mengubah kehidupan mereka. Disebabkan keputusan Sani cemerlang dalam mata pelajaran Sains Pertanian akhirnya Sani mendapat tawaran untuk melanjutkan pelajaran di UPM. Oleh itu, Sani bertekad untuk mencapai hasratnya membuka ladang anggur di tanah peninggalan bapanya. Sebagai anak muda yang berjiwa besar, Sani cuba membina legasi dirinya sendiri untuk menjadi mahasiswa, dia sangat aktif semasa di universiti sehingga dia berpeluang terbang ke Turki kerana terpilih untuk menghadiri persidangan di Istanbul. Walaupun Turki sebuah negara yang jauh, namun Sani tetap tabah untuk pergi ke sana demi kemajuan diri, kemajuan kampungnya dan masa hadapan. Sani juga bijak memanfaatkan peluang yang ada semasa berada di Turki untuk mencari ilmu pengetahuan tentang buah anggur. Dengan Pendidikan yang dimiliki, Sani berani melangkah lebih jauh ke depan untuk mencapai hasratnya sekali gus mengubah kehidupannya yang serba kekurangan.

Pendidikan memainkan peranan penting untuk mencapai hidup yang berkualiti kerana pendidikan merupakan antara petunjuk terpenting dalam kualiti hidup manusia. Pendidikan mempunyai hubungan rapat dengan ilmu, dan ilmu dikenal pasti sebagai faktor 'hasil'. Pendidikan membantu individu membina keyakinan diri untuk berhadapan dengan dunianya, menikmati kemudahan yang ada di persekitarannya, serta memahami diri sendiri. Taraf pendidikan yang baik memberikan seseorang individu itu laluan ke arah pembangunan diri, bergantung bagaimana ilmu tersebut distrukturkan dan dilaburkan dalam pendidikan. Justeru itu, pendidikan amat penting dalam pembangunan masa hadapan.

\section{Masyarakat yang Mengamalkan Sikap Tolong-menolong Sesama Manusia}

Tolong-menolong adalah sikap saling membantu untuk meringankan beban (penderitaan, kesulitan) orang lain dengan melakukan sesuatu. Pelbagai bantuan boleh disalurkan kepada mereka yang memerlukan sama ada bantuan dari tenaga, waktu, ataupun dana. Tolong-menolong merupakan satu sikap yang perlu ada dalam kehidupan bermasyarakat. Sebagai manusia yang mempunyai kemampuan yang berbeza-beza, kelebihan seseorang dalam sesuatu perkara dapat memberi manfaat bukan sahaja kepada diri sendiri bahkan kepada orang lain yang memerlukan bantuan. Begitu juga kelebihan orang lain akan memberi kebaikan kepada kita. Oleh itu, antara sikap dan nilai penting yang perlu ada dalam perhubungan sesama manusia ialah tolong-menolong.

Walaupun tolong-menolong merupakan perbuatan yang baik, namun adakalanya masih terdapat segelintir masyarakat yang belum memahami bahawa dalam tindakan tolong-menolong terdapat etika yang harus dipertimbangkan. Menolong seseorang haruslah berlandaskan keikhlasan kerana tujuan kita membantu adalah untuk meringankan beban dan kesusahan orang lain. Jangan sampai pertolongan tersebut mengharapkan balasan tertentu. Biarlah perbuatan baik kita dalam membantu orang lain dibalas oleh tuhan melalui orang-orang lain yang kita temui dalam kehidupan kita seharian. Kita tidak wajar mengharapkan orang yang kita bantu itu akan membalas semula perbuatan baik kita. Berdasarkan novel Semanis Kyuho terdapat pemikiran yang mengetengahkan tentang amalan tolong-menolong dalam kalangan masyarakat. hal ini digambarkan dalam petikan berikut: 
"Baiklah. Terima kasih, Pak Haji," ucap Sani, kemudian meminta rakanrakannya berhenti menjalankan kerja mereka. Dia mahu menziarahi Pak Halim. Sejak kecil lagi, Pak Halim hidup berjiran dengan keluarganya. Malah, Pak Halim banyak membantu keluarganya dahulu. Dia tahu ibunya sering ke rumah Pak Halim apabila mereka kekurangan belanja.

(Semanis Kyuho, 2016, p. 151-152)

Berdasarkan petikan tersebut dapat dilihat bahawa keluarga Pak Halim sering membantu keluarga Sani yang dalam kesusahan. Mak Dah sering ke rumah Pak Halim untuk meminta bantuan dari segi belanja rumah. Dengan kebaikan yang dimiliki oleh keluarga Pak Halim, keluarga Sani menerima bantuan tersebut tanpa segan. Keadaan itu telah menjadikan Sani terkesan dengan kebaikan yang dilakukan oleh keluarga Pak Halim sehinggakan Sani sanggup berhenti membuat kerja seketika untuk menghadiri majlis pengebumian Pak Halim. Tolong-menolong merupakan suatu kewajipan bagi setiap manusia. Sikap tolong-menolong dapat membina hubungan baik sesama manusia. Melalui pertolongan yang dihulurkan keluarga Pak Halim dapat meringankan beban keluarga Sani. Bantuan yang diberikan sangat bermakna bagi mereka.

"Aku tidak ada niat lain, selain membantu kau, Sani. Anggaplah kenangan zaman remaja kita sudah berlalu. Sekarang kita berhubung secara professional. Akan tetapi jika kau tidak setuju, aku tidak akan memaksa," balas Dalila. Ada nada sedih dalam suaranya.

(Semanis Kyuho, 2016, p. 167)

Selain itu, watak Dalila anak kepada Pak Halim bertekad untuk membantu bekas rakan karibnya, iaitu Sani sehingga berjaya. Dalila masih berasa bersalah dengan kesilapannya yang mempermainkan Sani semasa membeli buah anggur yang diinginkan oleh bapa Sani. Disebabkan kejadian itu, Dalila cuba untuk menebus kesilapannya dengan membantu Sani yang sedang berjuang untuk menjayakan projek rintisnya, iaitu membuka ladang anggur. Dalila sedia berkhidmat untuk menjadi pegawai perunding untuk projek Sani. Walaupun pada mulanya Sani menolak pertolongan yang diberikan oleh Dalila, namun akhirnya dia bersetuju untuk membenarkan Dalila memberi khidmat nasihat yang bersesuaian. Hal ini demikian kerana, Dalila tahu Sani memerlukan sokongan material dan psikologi. Keadaan ini secara tidak langsung dapat membantu Sani untuk mencapai impiannya.

Sikap tolong-menolong juga dapat membantu mengikis sikap negatif dalam diri seseorang, contohnya sikap suka mementingkan diri tanpa menghiraukan kewujudan orang di sekeliling. Bukan itu sahaja, amalan tolong-menolong juga merupakan satu amalan yang dapat memberi impak yang besar kepada pembangunan sosial yang baik dalam sesebuah masyarakat. Sikap menolong orang dalam kesusahan dan memudahkan urusan orang lain perlulah menjadi amalan dalam kalangan masyarakat hari ini. Oleh itu, sebagai sebuah masyarakat yang terdiri daripada pelbagai bangsa, kita perlulah mengamalkan sikap tolong-menolong kerana sikap ini penting dalam pembangunan sosial, iaitu masyarakat dalam proses untuk melahirkan masyarakat lebih bermutu. 


\section{Masyarakat yang Mempunyai Sikap Bersungguh-sungguh dalam Mencapai Impian}

Menurut Kamus Dewan Bahasa dan Pustaka (2009), bersungguh-sungguh bermaksud suatu perbuatan untuk bekerja kuat atau berusaha dengan sepenuh hati bagi memenuhi maksud perihal ketekunan, kerajinan dan kesungguhan seseorang. Bersungguh-sungguh juga didefinisikan sebagai suatu perbuatan untuk melaksanakan sesuatu dengan segenap hati dan sepenuh minat serta benarbenar berusaha dengan sekuat-kuatnya. Sifat bersungguh-sungguh pula merujuk kepada perbuatan melakukan sesuatu tugasan dengan sepenuh hati dan komited terhadap tugasan tersebut (Kamus Dewan, 2009). Oleh itu, bersungguh-sungguh boleh didefinisikan sebagai perbuatan untuk melakukan sesuatu secara serius dan bermatlamat berpandukan kepada sasaran serta matlamat perbuatan tersebut dilaksanakan (Kamus Dewan Bahasa dan Pustaka, 2009).

Menurut Hedley (2006), seseorang individu akan bersungguh-sungguh melakukan sesuatu pekerjaan, contohnya perniagaan kerana mereka sayang akan pekerjaan tersebut, manakala menurut Hewlett dan Luce (2006), sesetengah orang bekerja kuat untuk meningkatkan pendapatan dan taraf hidup pada masa hadapan. Konsep bekerja bersungguh-sungguh yang dihuraikan oleh Hedley (2006), Hewlett dan Luce (2006) ini boleh dicirikan sebagai sifat kesungguhan seseorang individu untuk berusaha keras mencapai kejayaan dalam hidup. Konsep bersungguh-sungguh boleh digunakan sebagai penggerak kepada motivasi dalaman individu (Locke \& Edwin, 1968) untuk berusaha mencapai taraf hidup yang lebih baik seperti penemuan kajian oleh Jurgen dan Anke (2001).

Pemikiran berkaitan kesungguhan dalam mencapai sesuatu impian dapat dilihat dilalui watak Sani yang berusaha bersungguh-sungguh dalam mencapai impiannya membuka ladang anggur. Berikut merupakan petikan dalam novel Semanis Kyuho yang memaparkan sifat kesungguhan watak Sani.

Kalau arwah bapanya masih ada, Sani mahu menjadikan arwah sebagai orang pertama yang merasai anggur tanamannya di ladang itu. Semuanya bermula kerana peristiwa Pak Sin kempunan untuk makan anggur. Akibat terasa dirinya dipermain-mainkan itulah Sani telah nekad. Impian itu telah dibawa sejak dulu. Impian dengan usaha yang gigih telah mencambahkan hasil.

(Semanis Kyuho, 2016, p. 188)

Kegagalan Sani untuk mendapatkan segugus anggur yang diinginkan oleh arwah bapanya telah menjadikan dia bangkit untuk membuka ladang anggur di tanah peninggal bapanya. Semenjak peristiwa Sani dipermainkan oleh Dalila untuk mendapatkan buah anggur, Sani mula menyimpan hasrat untuk membuka sebuah ladang anggur. Keadaan ini, menjadikan Sani berusaha lebih bersungguh-sungguh dalam mata pelajaran pertanian seperti yang dinasihati oleh Cikgu Tan Liang Tong. Dengan keputusan yang cemerlang Sani dapat melanjutkan pelajaran di Universiti Putra Malaysia. Banyak usaha yang dilakukan oleh Sani dalam mencapai impiannya. Walaupun banyak cabaran yang menimpa kehidupannya seperti kekurangan wang, cabaran daripada sikap tidak puas hati orang lain dan sebagainya. Namun, Sani tetap tabah menghadapinya. Kesungguhan Sani dalam mencapai impiannya membuatkan dia merantau menuntut ilmu mengenai penanaman buah anggur. Hal ini demikian, kerana baginya ilmu sangat penting untuk membantu dia membuka ladang anggur. 
Sani, Hasan dan Nilay berjalan seiring. Setiap kawasan ladang itu ditelusuri oleh Sani dengan penuh minat. Satu kawasan dikhususnya untuk menanam satu spesies anggur. Pelbagai spesies anggur ditanam untuk menghasilkan pelbagai jenis wain.

(Semanis Kyuho, 2016, p. 88)

Kesungguhan Sani untuk mempelajari ilmu selok-belok penanaman buah anggur telah membawanya ke Turki. Sani sampai di pusat pemprosesan wain tertua di Turki, yang ingin dilihat oleh Sani bukanlah wain tetapi dia mahu melawat salah satu ladang anggur milik syarikat Kavaklidere di Cappadocia. Sani juga telah menghubungi pegawai syarikat yang bernama Hasan sejak beberapa minggu yang lalu. Banyak ilmu yang dia pelajari mengenai penanaman anggur. Sani juga pergi ke Thailand untuk mempelajari ilmu mengenai pembajaan pokok anggur yang sangat penting bagi menggalakkan pertumbuhan pokok anggur dengan lebih cepat. Malahan, Sani menghasilkan baja kompos berasaskan tahi kambing yang dibeli dari kampung sebelah dan hasilnya amat memberangsangkan. Kesungguhannya untuk merantau telah menjadikan Sani menguasai dengan baik semua hal yang berkaitan dengan penanaman anggur. Kesungguhan Sani telah menjadikan impiannya sebagai suatu kenyataan, iaitu dia berjaya membuka ladang anggur dengan bantuan daripada pelbagai pihak.

Kesimpulannya, setiap orang mahukan kejayaan dalam hidup. Namun demikian, kejayaan tersebut tidak datang dengan sendirinya, sebaliknya, perlu disusuli dengan usaha yang bersungguhsungguh. Selain itu, kita juga perlu mempunyai semangat yang tinggi ketika menghadapi pelbagai cabaran dalam hidup dan dalam apa-apa jua keadaan. Untuk meraih sesuatu kejayaan, kita harus sentiasa berfikiran positif selain berusaha dengan bersungguh-sungguh. Belajar daripada kejayaan orang lain juga merupakan satu cara untuk kita mencapai apa-apa yang kita impikan.

\section{Masyarakat yang Mempunyai Sifat Hasad Dengki}

Hasad berasal daripada bahasa Arab yang bererti dengki, dan perkataan ini sering digabungkan menjadi hasad dengki dalam bahasa harian. Hasad dengki membawa maksud perasaan inginkan agar nikmat, kelebihan, kebolehan atau keistimewaan yang ada pada orang lain terhapus. Justeru, hasad dengki adalah sifat mazmumah yang paling kerap melanda diri manusia. Dalam menghuraikan persoalan sifat yang keji ini, Imam al-Ghazali menyenaraikan tiga ciri orang yang mempunyai sifat dengki, iaitu menginginkan agar kenikmatan atau kelebihan lenyap daripada orang lain dan mengharapkan agar kenikmatan itu berpindah kepadanya. Selain itu, mereka menginginkan kelebihan yang dimiliki orang lain itu lenyap meskipun mereka tidak dapat memilikinya disebabkan kekurangan yang ada pada diri mereka sendiri. Perkara yang penting baginya ialah orang itu jatuh dan hilang kelebihannya.

Sehubungan itu, seseorang yang berpenyakit hasad dengki sentiasa berasa gelisah atau tidak puas hati apabia melihat apa-apa yang dimiliki oleh orang lain. Apabila perasaan itu tidak lagi dapat dikawal, maka si pendengki akan menyusun strategi agar hasrat buruk itu tercapai dengan apa-apa cara sekalipun. Situasi inilah yang menatijahkan gejala negatif seperti merekareka cerita, memfitnah, mengumpat, memaki dan sebagainya bertujuan memburuk-burukkan orang yang didengki. Mereka yang mempunyai sikap hasad itu sanggup melakukan apa-apa sahaja untuk 
memuaskan kehendaknya. Berdasarkan novel Semanis Kyuho pemikiran berkaitan hasad dengki turut dibincangkan melalui watak dalam novel tersebut.

"Sani saya rasa awak mesti berhati-hati. Manusia akan berbuat apa sahaja untuk memuaskan hatinya. Barangkali ada pihak yang cuba menggagalkan projek awak ini," ujar Dr. Hani menasihati Sani. Daripada cerita yang di dengarnya Sani tidak terlepas daripada sikap dengki musuhnya. Budaya ini sudah lama bertapak dalam jiwa bangsa Melayu. Sikap dengki-mendengki sangat ketara. Namun, Sani tidak boleh menjadikan hal itu sebagai alasan untuk tidak maju. Untuk maju, cabaran besar ini perlu dihadapi.

(Semanis Kyuho, 2016, p. 158)

Berdasarkan petikan tersebut, pemikiran hasad dengki diperlihatkan melalui watak Rizwan memberi gambaran jelas tentang segelintir masyarakat yang mengamalkan budaya dengkimendengki. Disebabkan perasaan iri hati terhadap kelebihan yang dimiliki oleh orang lain telah mendorong dirinya untuk melakukan perkara yang boleh memudaratkan orang. Rizwan yang tidak pernah puas dengan kelebihan yang dimiliki oleh Sani sejak zaman persekolahan lagi menyebabkan dia sanggup melakukan apa-apa sahaja untuk memuaskan hatinya. Banyak hal yang telah dilakukan oleh Rizwan untuk menjatuhkan Sani seperti, meracuni tanaman buah anggur Sani dengan mengarahkan Khairil untuk melakukan perkara tersebut. Sani juga tidak menyangka bahawa Khairil telah menjadi tali barut Rizwan untuk menggagalkan projek tanaman buah anggur Sani. Khairillah yang meracuni pokok-pokok anggur di ladang Sani. Hal ini demikian kerana api dendam Rizwan terhadapnya belum lagi terpadam.

Selain itu, Rizwan juga mengupah seseorang untuk merosakkan brek kenderaan kepunyaan Dalila. Hanya untuk mendapatkan Dalila, dia sanggup bertindak sejauh itu, sedangkan Sani tidak lagi menaruh harapan tinggi terhadap gadis bekas jirannya. Sedangkan kehadiran semula Dalila itu hanya sebagai hubungan seorang pegawai perunding. Disebabkan kemalangan yang menimpa, Dalila patah kaki dan tidak boleh berjalan seperti biasa. Kesilapan yang dilakukan oleh Rizwan disebabkan sikap dengkinya yang menebal telah menyakitkan orang yang dia sayang. Hasad dengki Rizwan terhadap Sani telah menghukum dirinya sendiri. Rizwan telah ditahan dan akan dibicarakan atas tuduhan menyebabkan kematian orang awam. Jika disabit kesalahan di bawah Seksyen 302 Kanun Keseksaan, ada kemungkinan Rizwan akan berhadapan dengan hukuman mati. Khairil yang menjadi orang suruhannya pula kini telah ditahan polis.

Perasaan hasad dengki hanya akan menyebabkan kerugian kepada diri sendiri. Individu yang mempunyai hasad dengki akan terpinggir daripada hidup bermasyarakat, mempunyai perasaan yang sentiasa tidak aman dan akan menyebabkannya melakukan perkara-perkara yang lebih keji. Apabila di akhirat nanti, dia akan menanggung kerugian yang lebih besar, tidak tertanggung dan menempah penyesalan yang tidak terkira kerana tidak layak untuk menerima dan mendapat syafa'at dan tidak ditempatkan dalam tempat yang penuh kebaikan, kemewahan dan keberkatan, yakni syurga. Walaupun kerugian itu ditanggung secara personal oleh pengamalnya, akan tetapi turut memberi kesan yang tidak baik kepada ukhuwwah Islamiyyah. Umat Islam akan menjadi tidak bersatu dan tidak akan menjadi sebuah umat yang kuat sekiranya sifat ini diamalkan oleh orang-orang Islam. Akhirnya, umat Islam secara keseluruhannya yang akan rugi. 


\section{Kesimpulan}

Berdasarkan perbincangan, penulis menyimpulkan bahawa terdapat dua pemikiran yang dominan dalam novel Semanis Kyuho karya Ghazali Lateh ini, iaitu pemikiran dari aspek sosioekonomi dan pemikiran dari aspek sosiobudaya. Antara pemikiran yang ditemui dari aspek sosioekonomi ialah masyarakat yang mempunyai sikap rajin berusaha dalam meneruskan kelangsungan hidup dan kemiskinan dan kesempitan hidup yang dialami oleh penduduk kampung. Seterusnya, dari aspek sosiobudaya pula, pemikiran yang ditemui ialah masyarakat yang mementingkan pendidikan untuk masa hadapan, masyarakat yang mengamalkan sikap tolong-menolong sesama manusia, masyarakat yang mempunyai sikap bersungguh-sungguh dalam mencapai impian dan akhir sekali masyarakat yang mempunyai sifat hasad dengki. Kesemua pemikiran yang dinyatakan di atas dipaparkan menerusi watak-watak tertentu dalam novel Semanis Kyuho ini.

\section{Rujukan}

Arba'ie Sujud, Salhah Razak \& Siti Rabiatul Adawiah Jaffar. (2015). Pemikiran politik: Pemimpin dan kepimpinan dalam novel Shahnon Ahmad. International Journal of the World and Civilisation. 3(1), 67-78.

Asmah Hj. Omar. (1986). Bahasa dalam alam pemikiran Melayu. Kuala Lumpur: Dewan Bahasa dan Pustaka.

Ezzah'Afifah Nasrudin \& Che Ibrahim Salleh (2015). Pemikiran Melayu dalam cerita lipur lara. Journal of Business and Social Development, 63-79.

Farra Humairah Mohd. (2018). Pemikiran dalam cerpen kanak-kanak pilihan dari tahun 2012 hingga 2015. (PhD), Universiti Putra Malaysia.

Ghazali Lateh. (2016). Semanis Kyuho. Cheras: Utusan Publication \& Distributors Sdn. Bhd.

Kamus Dewan Bahasa Edisi Keempat. (2010). Kuala Lumpur: Dewan Bahasa dan Pustaka.

Kamus Pelajar Bahasa Malaysia Edisi Kedua. (1987). Kuala Lumpur: Dewan Bahasa dan Pustaka.

Marzalina Mansor, Nor Hafidah Ibrahim, \& Hasmawati Hassan (2016). Pemikiran dalam novel Sebalik Yamashita dan Percivel. International Seminar on generating knowledge through research, (pp. 101-112).

Masrizayu Mustafa. (2006). Pemikiran dalam novel-novel Khadijah Hashim. Tesis Sarjana yang tidak diterbitkan, Serdang: Universiti Putra Malaysia.

M. Jandra. (2010). Fenomena karya sastera novel berdimensi Islam dan perkembangannya dalam masyarakat nusantara. Jurnal Pengajian Melayu/Journal of Malay Studies (JOMAS), Jilid 21, 96-110.

Nurhamizah Hashim. (2015). Psikologi keperluan remaja dalam novel-novel remaja Hadiah Sastera Kumpulan Utusan (HSKU). (Ph. D), Universiti Malaya, Kuala Lumpur. 
Pemikiran Dalam Novel Semanis Kyuho Karya Ghazali Lateh

Nurmaizatul Anis Ahmad \& Halis Azhan Mohd Hanafiah. (2019). Pemikiran Islam dalam konteks sosioekonomi dalam kumpulan cerpen Cahaya Pelita Nurani. Jurnal Pengajian Melayul Journal of Malay Studies (JOMAS), Jilid 30, 167-87.

Noorhazwany Ariffin \& Noryamisma Ismail. (2014). Pemikiran Marzuki Ali dalam Khazanah Segala Rimbun dari aspek Teori Pengkaedahan Melayu. Jurnal Pengajian Melayu/Journal of Malay Studies (JOMAS), Jilid 25. 130-152.

Samsudin Ahmad. (2000). "Sajak-sajak Masuri S.N.: Analisis pemikiran dan bentuk luaran”. Tesis Sarjana. Universiti Putra Malaysia.

S. Othman Kelantan. (1999). Pemikiran satira dalam novel Melayu. Kuala Lumpur: Dewan Bahasa dan Pustaka.

Siti Khairiah Mohd Zahir dan Nur Aisyah Abdullah. (2014). Pemikiran Khadijah Hashim dalam novel Badai Semalam dan Laila Gadisku untuk membangunkan sahsiah belia. Jurnal Bahasa dan Sastera Melayu. Volume 5, 140 -165.

Siti Khairiah Mohd Zubir dan Norol Nizam bin Sarkawi. (2011). Pemikiran pengarang dalam novel Jeriji Kasih karya Ramlah Abdu Rashid. Jurnal Pusat Penataran Ilmu dan Bahasa. Volume 17, 147-169.

Siti Norashikin Mohd Khalidi, Nor Azuean Yaakob \& Zaitul Azma Zainon Hamzah. (2017). Makna Siratan Bahasa Figuratif dalam Cerpen Melayu Karya Lim Swee Tin. Journal of Business and Social Development, 75-94.

Yusof Rahim. (2010). Asas sains sosial: Dari perspektif sosiologi. Kuala Lumpur: Dewan Bahasa dan Pustaka.

Zainal Kling. (1989). Pemikiran sosiopolitik Melayu II. Kuala Lumpur: Dewan Bahasa dan Pustaka. 